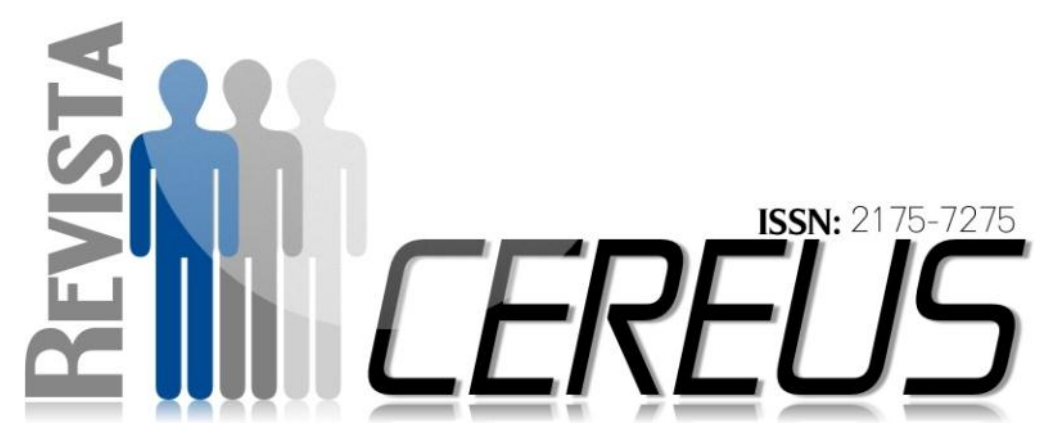

DOI:10.18605/2175-7275/cereus.v9n1p.178-192

\title{
PERFIL SOCIODEMOGRÁFICO E CLÍNICO DE PACIENTES ADULTOS HIV (+), ATENDIDOS NA POLICLÍNICA MUNICIPAL DE GURUPI-TO
}

PEREIRA, Michael Gomes ${ }^{1}$

VALE, Márcia Adriane da Costa ${ }^{1}$

GONTIJO, Érica Eugênio Lourenço ${ }^{2}$

SILVEIRA, Janne Marques ${ }^{3}$

MARRONI, Marcia Andrea ${ }^{4}$

SILVA, Marcos Gontijo da ${ }^{5}$

\section{RESUMO}

Trata-se de um estudo descritivo de abordagem qualitativa, realizado na Policlínica Municipal de Gurupi-TO departamento de DST/HIV/AIDS, no período de agosto a outubro de 2016 cujo objetivo foi identificar e caracterizar o perfil clinico e sócio demográfico de pacientes adultos HIV positivos atendidos no local. A pesquisa se deu por meio de analise retrospectiva em fichas semiestruturada. Os sujeitos do estudo foram pacientes cadastrados no Programa Municipal de DST/HIV/AIDS no município de Gurupi. Foram

${ }^{1}$ Graduados em Farmácia Generalista, Centro Universitário UNIRG.

${ }^{2}$ Doutora em Ciências da Saúde pela faculdade de Medicina da Universidade Federal de Goiás, HC-UFG, Professora auxiliar do curso de Farmácia do Centro Universitário UNIRG, Gurupi-TO. E-mail: ericagontijo1@yahoo.com.br

${ }^{3}$ Mestre em Fisioterapia Cardiovascular e Respiratória pelo Centro Universitário do Triângulo. Graduada em Fisioterapia. Professora Adjunta de fisiologia humana no curso de Medicina do Centro Universitário UNIRG, Gurupi-TO.

${ }^{4}$ Doutora em Saúde do Adulto pela Escola de Enfermagem da USP. Graduada em Enfermagem e Obstetrícia. Professora titular no centro Universitário de Gurupi, UNIRG -TO

${ }^{5}$ Doutor em Medicina Tropical e Saúde Pública pelo Instituto de Patologia Tropical e Saúde Pública. Biomédico. Professor Titular de Parasitologia do Centro Universitário UNIRG, GurupiTO. E-mail: gontijobio@yahoo.com.br

v. 9, n. 1, jan/abr. 2017 UnirG, Gurupi, TO, Brasil 
analisadas informações de 97 pacientes, 65\% do sexo masculino, a maioria dos pacientes heterossexuais e pessoas pardas com idades entre 40 e 49 anos. Conclui-se que a população de pessoas HIV+ em Gurupi é grande, formadas em sua maioria por homens, heterossexuais e pardos e que necessitam de atenção especial do poder público, quanto ao acompanhamento clínico laboratorial e psicológico.

Palavras-chave: HIV. Síndrome de Imunodeficiência Adquirida. Perfil clínico e sociodemográfico.

\section{SOCIODEMOGRAPHIC AND CLINICAL PROFILE OF ADULT HIV (+) PATIENTS, ATTENDED AT THE MUNICIPAL POLYCLINIC OF GURUPI-TO}

\section{ABSTRACT}

SUMMARY: This is a descriptive study of quantitative approach, carried out in the Municipal Polyclinic of GurupiTO department of STD / HIV / AIDS, from August to October 2016, whose objective was to identify and characterize the clinical and demographic profile of adult patients (HIV +) treated at the clinic. The research was done by means of retrospective analysis in semistructured records. The study subjects were patients enrolled in the Municipal STD / HIV / AIDS Program in the municipality of Gurupi. We analyzed 97 charts of patients, $65 \%$ of males, the majority of heterosexual patients and brown people between the ages of 40 and 49 years. It is concluded that the population of HIV $(+)$ people in Gurupi is large, composed mostly of men, heterosexuals and browns and who need special attention from the public government, regarding clinical laboratory and psychological monitoring.

Key Words: HIV. Acquired Immunodeficiency Syndrome.

Clinical and sociodemographic profile. 


\section{INTRODUÇÃO}

A AIDS teve início na África há mais de quarenta anos atrás e no início dos anos 80 começou a atingir pessoas de classes sociais mais altas e pessoas de primeiro mundo. Quando a epidemia se iniciou atingia as pessoas na faixa etária de 20 a 45 anos, principalmente usuários de drogas injetáveis e homossexuais. Acredita-se que a doença se espalhou para a américa devido o continente africano estabelecer uma imigração de africanos infectado para o EUA atrás da seguinte rota: África Haiti-EUA (AGUIAR e RIBEIRO, 2006).

O HIV (Vírus da Imunodeficiência Humana) é transmitido primeiramente através de relações sexuais (heterossexual ou homossexual), transfusões sanguíneas, agulhas contaminadas por usuários de drogas endovenosas, da mãe para o feto por via transplantaria, e da mãe para o lactante através da amamentação (SHARON; GUANABARA, 2000). Foram encontrados e descritos dois tipos de HIV, HIV-1 e HIV-2. O HIV-1 é o tipo mais virulento e o HIV-2 é mais encontrado na África ocidental (COICO, SUSHINE 2002, pag. 214.).

Estima que no mundo 35,3 milhões de pessoas vivem com o HIV/AIDS no ano de 2013, segundo a Organização Mundial de Saúde. Observa-se uma diminuição no número de infectados e no número de óbitos relacionados ao HIV no cenário mundial. Em 2013 ocorreram cerca de 2,3 milhões de novas infecções pelo HIV em comparação com 2001 que teve cerca 3,4 milhões de infectados. No ano de 2012 o número de óbitos foi de 1,6 milhões, um terço menor que o previsto em 2005, 2,3 milhões (WHO et al., 2013).

Foram notificados no SINAN (Sistema de Informações de Agravos de Notificação) no Estado do Tocantins em 2014, 112 casos de AIDS e 131 casos de infecção pelo HIV (BRASIL, 2014). Assim, essa doença é um grave problema na realidade do estado e por isso entender as características epidemiológicas e as características das pessoas infectadas é fundamental para que se possa traçar medidas mais eficazes de enfrentamento e controle.

Dessa forma este trabalho visa avaliar o perfil sociodemográfico e clínico de pacientes HIV+ atendidos na Policlínica Municipal de Gurupi- 
Tocantins.

\section{METODOLOGIA}

O presente estudo é do tipo retrospectivo de base populacional conduzido em Gurupi -TO, Brasil. A coleta de dados foi feita na Policlínica municipal Luiz Santos Filho, no bairro central de Gurupi.

Este inquérito é de prevalência do tipo retrospectivo.

A população estuda foi composta 97 (noventa e sete) pacientes $\mathrm{HIV}_{+}$atendidos na policlínica de Gurupi-TO, diagnosticados com HIV atendidos no período de janeiro de 2010 a janeiro de 2016.

As variáveis estudadas foram: idade, etnia, renda, origem, tempo de infecção, sinais e sintomas, tipo de tratamento, principais efeitos colaterais, índice de abandono e prognóstico.

\section{RESULTADOS}

As investigações mostram que as prevalências de infecção pelo HIV em Gurupi e região. Quanto ao gênero, a maior concentração dos
A pesquisa foi autorizada pelo Comitê de Ética (Parecer número: 1.256.985). Os riscos da pesquisa foram mínimos, sendo a possibilidade de exposição da identidade dos participantes. Como medidas para minorar os riscos, o manuseio dos prontuários foram feitos unicamente pelo pesquisador em sala fechada e em sigilo total.

A Policlínica de Gurupi possui sala de arquivo separado onde são arquivados todos os prontuários dos pacientes. Foram analisados todos os prontuários de pacientes entre 2010 e 2016 de onde foram extraídas as informações da pesquisa.

As informações foram inseridas em planilha computadorizada do programa Excel 2015. Após foi tratada por estatística descritiva sendo exposto por gráficos e tabelas.

casos de HIV foi em indivíduos do sexo masculino (65\%).

A respeito da idade, observa-se que a maior proporção é de 40 a 49 anos com o total de 29 pacientes. Em 
segundo está a faixa etária de 19 a 29 anos totalizando 28 casos (Figura 1).

Observa-se um número elevado de pacientes da cidade Gurupi representando 66 casos notificados e 30 pacientes de cidades próximas (Figura 2).

Dentre os casos de HIV/AIDS atendidos nos últimos cinco anos em Gurupi e Região, observaram-se as maiores taxas de incidência de casos de HIV+ são de origem da zona urbana (93\%).

Quanto à alteração da massa corporal 60 pacientes (61.85\%) tiveram um ganho de peso após o início do tratamento um aumento médio de $6.232 \mathrm{Kg}$ (Tabela 1 ).

Em relação à categoria de exposição heterossexual entre os individuo, observa-se uma leve estabilização na região em torno de $71 \%$ dos casos nos últimos cincos anos. Estão apresentadas as proporções de indivíduos com mais de 18 anos segundo as categorias de exposição HSH observa-se uma proporção inferior totalizando $23 \%$ dos indivíduos atendidos (Figura 3).

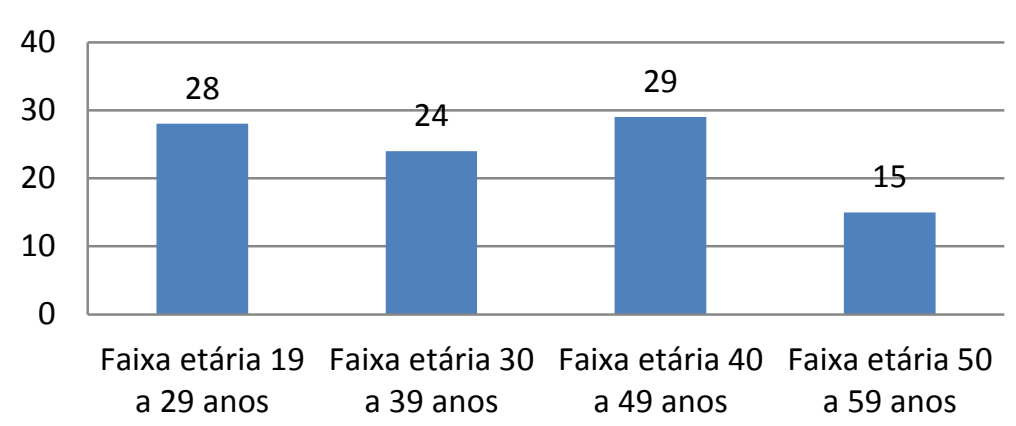

Figura 1: Faixa etária dos pacientes atendidos na policlínica municipal de Gurupi, Tocantins 2016

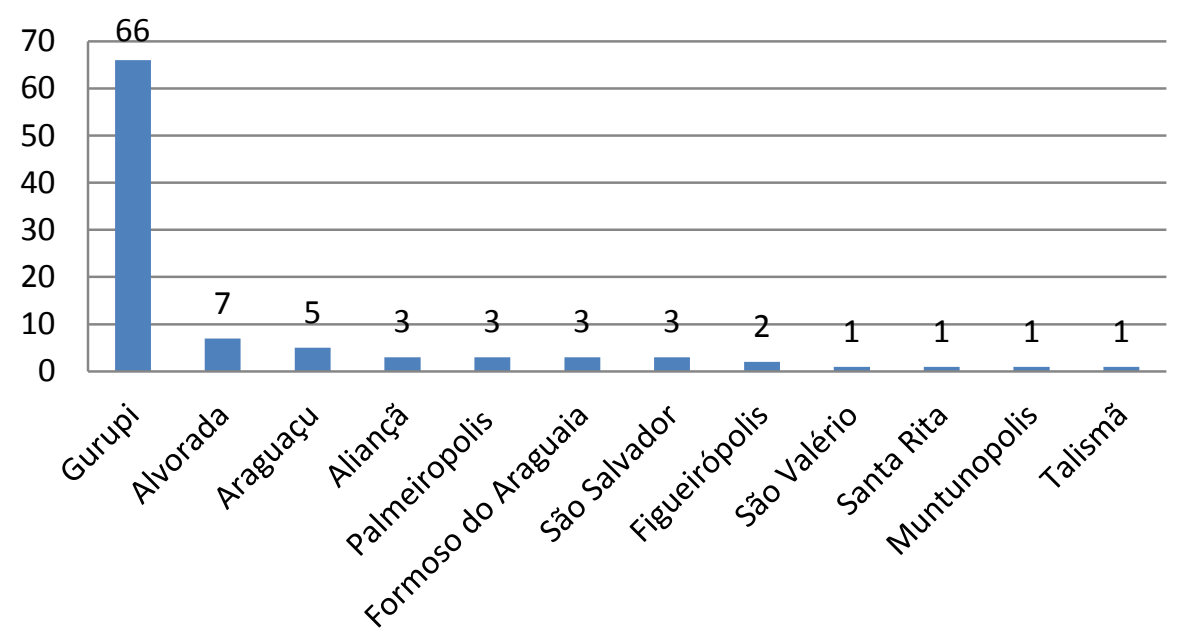

Rev. Cereus, v. 9, n. 1, p.178-192 , jan-abr./2017, UnirG, Gurupi, TO, Brasil. 
Figura 2: Cidade de origem dos pacientes HIV+ atendidos na policlínica municipal de Gurupi, Tocantins 2016

Tabela 1: Alteração de massa corporal nos pacientes HIV+ atendidos na policlínica municipal de Gurupi, Tocantins 2015

\begin{tabular}{lccc}
\hline & n. & $\%$ & Média de massa corporal perdida ou ganha em quilos \\
\hline Ganho de peso & 60 & 61.85 & 6.232 \\
Perda de Peso & 37 & 38.15 & 2.922 \\
\hline
\end{tabular}

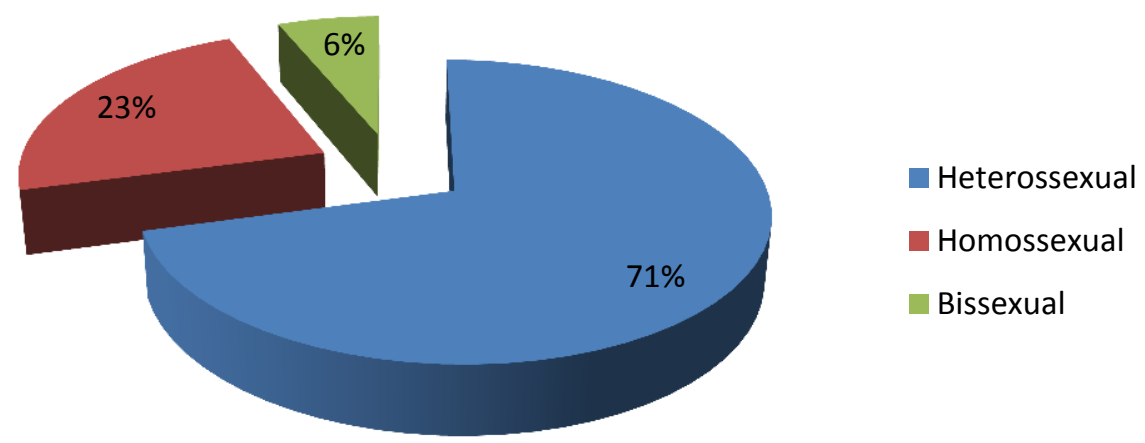

Figura 3: Opção sexual dos pacientes HIV+ atendidos na policlínica municipal de Gurupi, Tocantins 2015

Segundo a raça/cor, 57\% dos casos notificados na policlínica são Pardos, 28\% Brancos e 15\% Pretos (Figura 4).

Em relação ao esquema de tratamento utilizado pelos pacientes, os mais utilizados no esquema três em um são (TDF + 3TC + EFV) (Figura 5).

E com a ajuda da TARV $62 \%$ dos casos tratado na policlínica estão com os linfócitos acima do normal graças ao uso continuo é correto da medicação
Dentre as principais confecções acompanhadas pelo HIV está à sífilis que representou 18 casos notificados na Policlínica Municipal de Gurupi-TO (Figura 6).

Dentre os indivíduos que fazem o uso da TARV atendidos pelo SAE de Gurupi, cerca de 48\% apresentou alguma queixa ou resistência à medicação.

Quando ocorre a infecção pelo vírus causador da AIDS, o sistema imunológico começa a ser atacado. E 
é na primeira fase, chamada de período varia de 3 a 6 semanas. infecção aguda, que ocorre a Dentre os sintomas apresentado, incubação do HIV tempo da exposição emagrecimento teve representado em ao vírus até o surgimento dos 20 pacientes, febre foi acometido em primeiros sinais da doença. Esse 14 pacientes com febre (Figura 7 ).

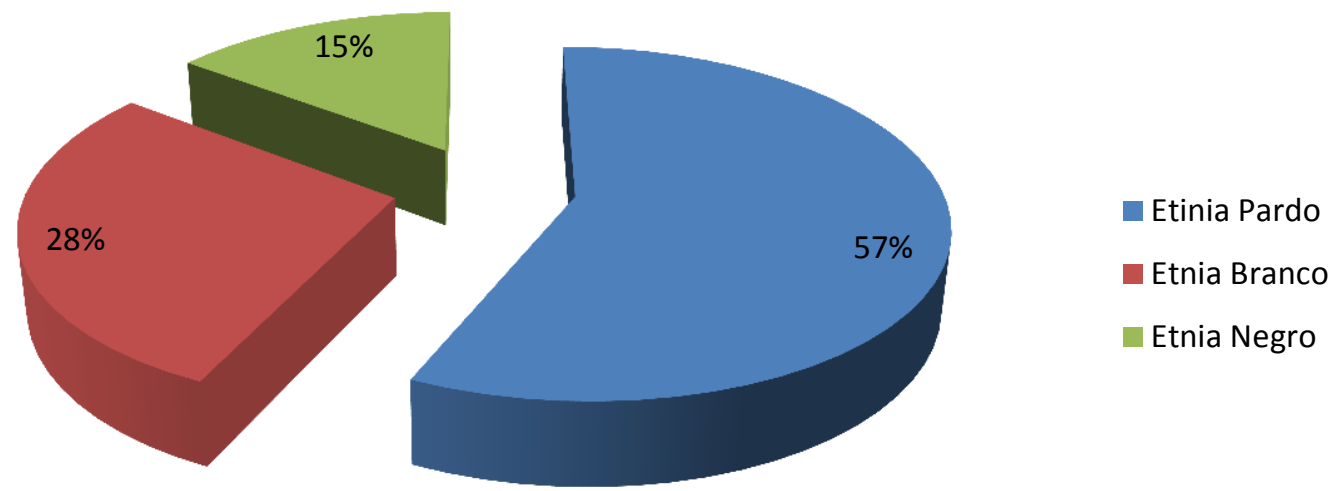

Figura 4: Etnia dos pacientes HIV+ atendidos na policlínica municipal de Gurupi, Tocantins 2016

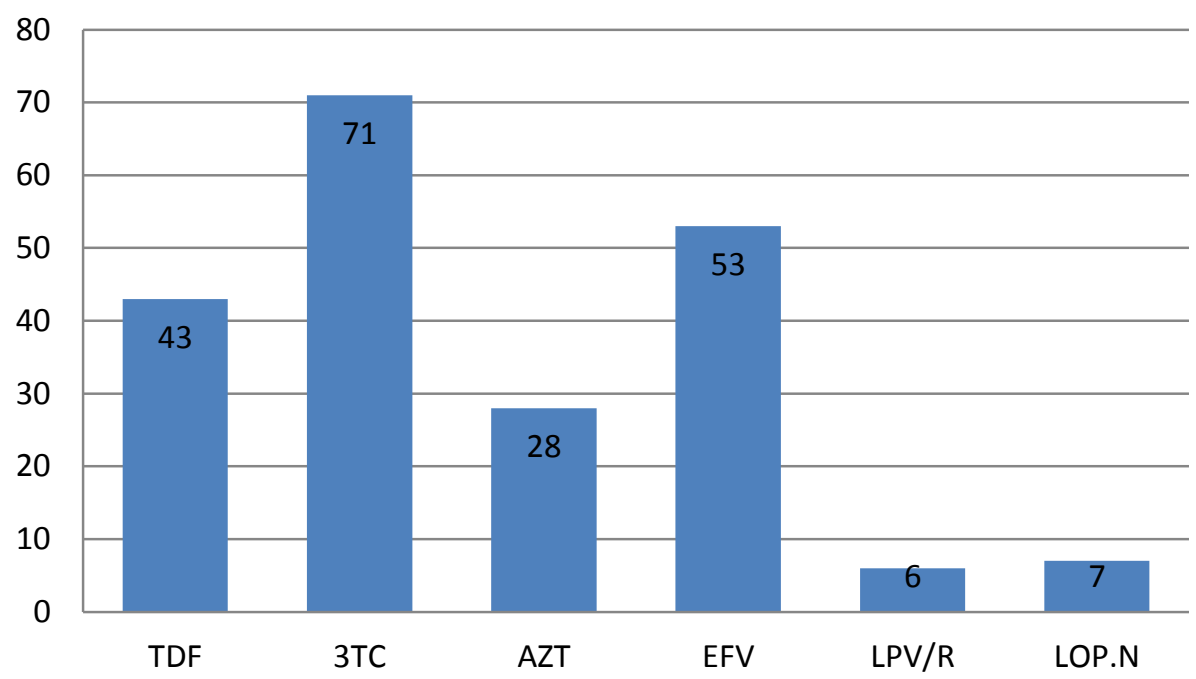

Figura 5: Medicamentos usados pelos pacientes HIV+ atendidos na policlínica municipal de Gurupi, Tocantins 2016 


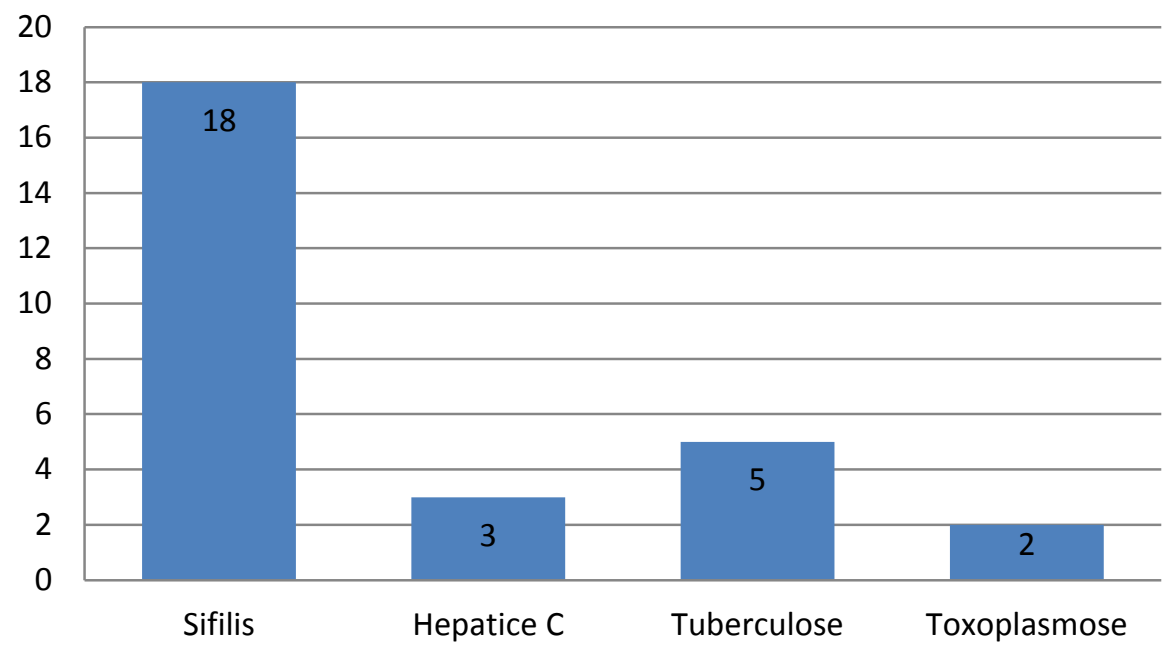

Figura 6: Principais co-infecções encontradas nos pacientes HIV+ atendidos na policlínica municipal de Gurupi, Tocantins 2016

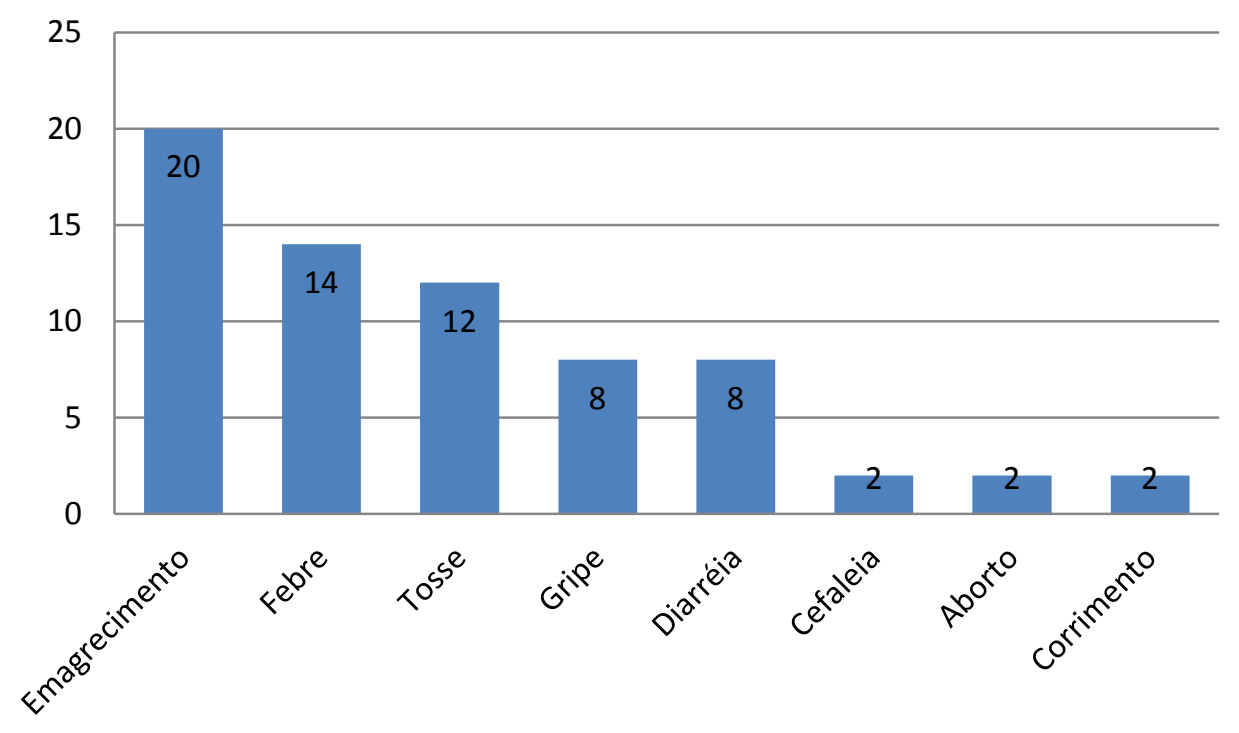

Figura 7: Principais queixas clínicas pelos pacientes HIV+ atendidos na policlínica municipal de Gurupi, Tocantins 2016

\section{DISCUSSÃO}

Nos últimos 30 anos a epidemia de AIDS trouxe consequências muito devastadoras para muitas famílias pelo mundo, sendo um dos maiores desafios para a saúde pública. Mais de 7.000 pessoas são infectadas com 0 vírus todos os dias, e uma pessoa morre a cada 20 segundos de uma doença oportunista relacionada à AIDS. A doença é atualmente a $5^{\mathrm{a}}$ causa de óbitos entre adultos e a principal causa entre as mulheres com 
idades entre 15 e 49 anos (ALVES, 2014).

A razão de sexo apresenta diferenças regionais importantes. Nas regiões Sudeste e Centro-Oeste, há um predomínio de homens em comparação com as demais regiões; a razão de sexo é de 21 casos em homens para cada 10 casos em mulheres, com tendência significativa de crescimento. Nas regiões Norte e Nordeste, a razão de sexo é em média 17 casos em homens para cada 10 casos em mulheres, enquanto que na região Sul há uma participação maior das mulheres nos casos de AIDS, em que a razão de sexo é de 15 homens para cada 10 mulheres (BRASIL, 2014).

A taxa de detecção dos últimos dez anos segundo faixa etária, entre as mulheres, apresenta tendência significativa de aumento entre aquelas com 15 a 19 anos, 55 a 59 anos e 60 anos ou mais, sendo o aumento de $10,5 \%, 24,8 \%$ e $40,4 \%$ de 2004 para 2013, respectivamente. Em relação às faixas etárias de 20 a 24 anos até 40 a 44 anos, observa-se, de 2004 a 2013, uma tendência significativa de queda. Nas demais faixas etárias, exceto as de crianças até 9 anos, observa-se estabilização das taxas ao longo dos últimos dez anos (BRASIL 2013).

Desde o início a doença se concentrou no sexo masculino, devido à doença ser mais frequente em homens homossexuais, se passaram mais de 30 anos mesmo assim a doença continua a se concentrar predominante no sexo masculino segundo dados epidemiológicos do Brasil e do mundo de 2014. Segundo a pesquisa levantada em Gurupi na $\mathrm{SAE}$, os dados não foram diferentes. A doença aqui no município e região é predominante em indivíduos do sexo masculino, afetando $65 \%$ dos integrantes desta pesquisa e apenas $35 \%$ do sexo feminino não havendo, assim, feminização em Gurupi como em outras partes do pais.

Quanto à faixa etária, a mais afetada foi a de 40 a 49 anos, diferente de estudos que mostraram que a doença ocorre em idades menores, na faixa de 15 a 24 anos (BRASIL, 2014).

Quanto à origem dos pacientes, foi observado que o numero de pacientes da zona rural infectados, foi de $7 \%$. Se for levado em consideração à diferença em termos de quantidade em relação às pessoas que vivem na zona rural e na zona urbana a diferença é muito grande. Então este 
valor tem que ser observado como um sinal da ruralização do vírus HIV. Isto serve de alerta e instigou a formulação da hipótese que devido a essa população rural ser menos escolarizada, talvez não tenham conhecimento sobre as formas de prevenção desta infecção, dai existe a necessidade do sistema público de saúde oferecer orientações por meio de aconselhamento, palestras sobre os riscos e como evitar a doença.

Em trabalho anterior feito por Sousa et al., (2015) com gestantes da Policlínica municipal de Gurupi foi observado que $16,6 \%$ das mulheres eram da zona rural, dado diferente do observado na população de forma geral.

Atualmente o tratamento usado é muito eficaz e possui grande capacidade de melhorar a qualidade de vida do portador do vírus. Isso pôde ser visto neste trabalho pela variação da massa corporal dos pesquisados. Tradicionalmente a principal manifestação da AIDS é o emagrecimento, porém isso foi pouco encontrado. Nessa pesquisa 97 pacientes, o que equivale a $61.85 \%$ tiveram ganho de peso, sendo que a média de ganho foi de $6.232 \mathrm{~kg}$.
Quanto à opção sexual é observado entre os homens 0 predomínio da exposição heterossexual; porém, há uma tendência de aumento na proporção de casos em homossexuais nos últimos dez anos, passando de 34,6\% em 2004 para 43,2\% em 2013. A proporção de usuários de drogas injetáveis (UDI) vem diminuindo ao longo dos anos em todo o Brasil, com tendência estatisticamente significativa de queda (BRASIL 2013).

Quando se iniciou, a epidemia atingia pessoas na faixa etária entre 20 a 45 anos, principalmente usuários de drogas injetáveis e homossexuais (AGUIAR e RIBEIRO et al., 2006).

De acordo com Aguiar (2006), a AIDS desde início da epidemia é uma doença homossexualizada devido o número de homens gays atingidos. De acordo com boletim epidemiológico do ano de 2013, isso não mudou a doença continua concentrada em maior frequência em homossexuais. $A$ pesquisa feita demostra que em Gurupi e região $23 \%$ dos casos registrado se declararam ser homossexuais, $6 \%$ bissexuais e $71 \%$ heterossexuais. Mostrando assim, que em Gurupi e região a doença também tem caráter homossexual, se levado 
em consideração que a proporção desta opção sexual na população não infectada.

Comparando-se a distribuição proporcional dos casos de AIDS segundo raça/cor por sexo desde 2004 até 2013, observa-se que não existe diferença estatisticamente significativa nas proporções de brancos, amarelos, pardos e indígenas segundo sexo, exceto entre os pretos, nos quais a proporção de homens é inferior à das mulheres. Em 2013, 9,7\% dos casos de AIDS notificados no SINAN entre homens eram em pretos, enquanto que entre as mulheres esse percentual foi de $11,7 \%$. Nesse mesmo ano, as proporções entre as raças branca, amarela, parda e indígena, no total dos casos, foram de $44,5 \%, 0,4 \%, 44,3 \%$ e $0,3 \%$, respectivamente. Além disso, tem-se observado um aumento significativo na proporção de casos entre os indivíduos autodeclarados como pardos e uma queda significativa na proporção de branco (BRASIL 2013).

Neste trabalho, os pacientes atendidos pelo SAE foram semelhantes pois $57 \%$ dos casos notificados eram pardos, $28 \%$ brancos e $15 \%$ pretos, porem diferentes dos encontrados por Sousa et al., (2015) com gestantes da Policlínica municipal de Gurupi foi observado que 53.3\% das mulheres eram Brancas.O acesso universal e gratuito à terapia antirretroviral (TARV), implantado no Brasil desde 1996, causou importante impacto na morbimortalidade por AIDS (FAZITO-REZENDE et al., 2010), com aumento da sobrevida de pessoas vivendo com HIV/AIDS (PVHA) (CHEQUER et al., 1992).

Em dezembro de 2013, o Brasil deu outro passo inovador e de vanguarda para a resposta à epidemia de HIV/AIDS: tornou-se o primeiro país em desenvolvimento e o terceiro do mundo a recomendar o início imediato da TARV para todas as PVHA, independentemente da contagem de CD4, considerando a motivação do paciente (BRASIL, 2013). A implementação do tratamento como prevenção (TasP) tem sido reconhecida como uma das mais importantes medidas de saúde pública para o controle da transmissão do HIV (HULL 2014; MONTANER 2010).

Nesse contexto,

0 monitoramento clínico das PVHA, incluindo a cascata de cuidado contínuo, torna-se essencial para se conhecerem os esforços necessários a maximizar os efeitos das intervenções 
e nortear as ações para conter 0 avanço da epidemia de HIV/AIDS (NOSYK, 2014).

A cascata de cuidado contínuo para o Brasil, em 2013. Nesse ano, estima-se que 734 mil pessoas vivam com o HIV/AIDS, das quais 80\% (589 mil) já haviam sido diagnosticadas. Aproximadamente dois terços (537 mil) das PVHA estavam vinculadas a algum serviço de saúde e 448 mil (61\%) continuaram retidas no serviço. Das 355 mil PVHA que estavam em TARV, em 2013, 293 mil apresentaram supressão da carga viral CV, com valor inferior a 1.000 cópias $/ \mathrm{mL}$, e 255 mil possuíam carga viral indetectável (inferior a 50 cópias $/ \mathrm{mL}$ ) (NOSYK, 2014).

Um dos pontos mais importantes para o sucesso da implementação do tratamento como prevenção é o diagnóstico oportuno da infecção pelo HIV (MONTANER, 2013). Internacionalmente, O monitoramento da ampliação diagnóstico é realizado pelo acompanhamento da proporção de PVHA virgens de tratamento que chegam ao serviço de saúde com comprometimentos imunológicos, esses últimos medidos pelo valor do CD4 (WHO, 2013).
A doença não tem cura, porém o tratamento eficaz para combater 0 HIV, no entanto só é eficaz se utilizado de maneira correta e continua. A melhora é medida pela dosagem dos linfócitos TCD4+ que tendem a aumentar e em contrapartida ocorre à redução da carga viral e a restauração do sistema imunológico do individuo, podendo ate levar a carga indetectável. Dos 97 pacientes da pesquisa $62 \%$ dos pacientes teve o nível de CD4+ acima do normal (acima de $350 \mathrm{~mm} 3)$, demostrando a eficácia do tratamento na maioria dos pacientes.

O TARV não é uma emergência, mas deve ser iniciado assim que possível e que as condições propiciarem. $\mathrm{O}$ tratamento das infecções oportunistas é prioritário. No caso de doentes com imunossupressão avançada (CD4 < $200 \mathrm{cel} / \mathrm{mm} 3)$ e doença oportunista ativa, é recomendado o início do TARV 15 dias após o início do tratamento da infecção oportunista. Sempre que possível o TARV e a profilaxia com CTZ não devem ser iniciados em simultâneo. Iniciar CTZ o mais precocemente possível e no mínimo 2 semanas antes do início do TARV, para que, caso ocorra alguma reação 
medicamentosa, seja possível melhor definir o fármaco responsável (MONTANER, 2013).

Os principais efeitos adversos não severos observados devido o uso da medicação são náuseas, vômitos, dores abdominais e diarreia. Os dados da pesquisa comprova que $48 \%$ dos pacientes apresentou alguma queixa devido o uso da TARV.

AIDS é uma doença sexualmente transmissível de fácil contagio, mais a falta do preservativo pode acarretar além do HIV outras doenças. Na presente pesquisa feita através de prontuários de soro positivo na SAE de Gurupi mostra que dos 97 pacientes estudados, 28 apresentaram alguma co-infecção juntos com o HIV, podendo dificultar ainda mais 0 possível tratamento para a doença.

Essas doenças acometidas nestes pacientes na maioria das vezes são diagnosticadas junto com o HIV, o

\section{CONSIDERAÇÕES FINAIS}

O perfil sociodemográfico dos infectados no trabalho foi de: homens com idade entre 40 e 49 anos, de origem urbana com predominância de heterossexuais, apresentando coinfecção com sífilis. que serve pra reforça a provável vida promiscua que estes indivíduos vivem. A sífilis doença sexualmente transmissível foi acometidas em maior número, sendo diagnosticada em 18 pacientes.

A AIDS é uma doença que degrada e mata o sistema imunológico do individuo, deixa a imunidade sem força pra reagir a qualquer invasor, ou seja, o organismo fica vulnerável a quaisquer doenças oportunistas que passam a ser um serio problema levando $\mathrm{o}$ individuo ate a morte. $\mathrm{Na}$ fase assintomática da doença começa a aparecer sinais e sintomas que por muitas vezes passam despercebidos ate virar problemas crônicos, 68 pacientes da pesquisa relataram ter queixas clinicas dentre elas, emagrecimento, febre, tosse diarreia entre outro como foi encontrado nesse trabalho.

Os dados poderão servir de suporte aos gestores para traçarem políticas públicas específicas para este grupo de forma mais assertivas e específicas, gerando economia 
financeira e otimização técnica da gestão

pública.

\section{REFERÊNCIAS}

AGUIAR, Zenaide Neto; RIBEIRO, Maria Celeste Soares. Vigilância e Controle das Doenças Transmissíveis. 2. ed. São Paulo: Martinari, 2006.

Alves T., M. Franco R. L., Kerr S., Kendall C., Mota R. M. S. Cenário Epidemiológico da Infecção pelo HIV e AIDS no Mundo. Rev Fisioter S Fun., 2014 Jan- Jun; 3(1):47 Disponivel em

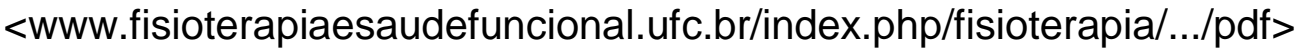

BRASIL. Boletim Epidemiológico-Aids/DST. In: PNDST/Aids, editor. Brasília: Ministério da Saúde; 2013.

BRASIL. Boletim Epidemiológico-Aids/DST. In: PNDST/Aids, editor. Brasília: Ministério da Saúde; 2014.

CHEQUER, P.; HEARST, N.; HUDES, E. S.; CASTILHO, E.; RUTHERFORD, G.; LOURES, L. et al. Determinants of survival in adult Brazilian AIDS patients, 1982 1989. The Brazilian State AIDS Program Co-Ordinators. AIDS, [S.I.], v. 6, p. 483-7, 1992.

COICO, R; SUSHINE G. Imunologia. Rio de Janeiro. Guanabara koogam.2014, pag. 214.

FAZITO-REZENDE, E. L. L.; VASCONCELOS, A. M. N.; PEREIRA, M. G. Causes of death among people living with HIV/AIDS in Brazil. Braz. J. Infect. Dis., [S.I.], v. 14, n. 6 , p. 558-563, 2010.

HULL, M.; LANGE, J.; MONTANER, J. S. Treatment as Prevention - Where Next? Curr. HIV/AIDS Rep., [S.I.], 12 nov. 2014. No

MONTANER, J. S. G. Treatment as prevention: toward an AIDS-free generation. Top. Antivir. Med., [S.I.], v. 21, n. 3, p.110-4, jul.-ago. 2013.

NOSYK, B.; MONTANER, J. S. G.; COLLEY, G.; LIMA, V. D.; CHAN, K.; HEATH, K. The cascade of HIV care in British Columbia, Canada, 1996-2011: a

SHARON U. Imunologia Básica. Rio de Janeiro; Ed. Guanabara Koogan. 2000, pág. 208. 
SOUSA, S.F.; XAVIER, Millena P.; BORGES, J.C.M.; ROCHA, K.A. Perfil de gestantes com HIV assistidas na policlínica de Gurupi-TO. Revista CERESUS. v. 7, n. 3, p.163-175, 2015.

WHO. Global report: UNAIDS report on the global AIDS epidemic 2013. WHO Library Cataloguing-in-Publication Data; 2013. 198p.

Recebido em: 11/12/2016

Aprovado em: 29/03/2017 